\title{
KISTA ARACHNOID EKSTRADURAL
}

\author{
Shinta Qorina1', Roni Eka Sahputra²
}

\begin{abstract}
Abstrak
Kista arachnoid ekstradural di tulang belakang merupakan kista yang langka dan jarang sebagai penyebab kompresi sumsum tulang belakang dan kista ini paling sering terjadi pada bagian tengah dan bawah dari tulang belakang. Kista arachnoid paling sering terjadi pada bagian tengah dan bawah tulang belakang $65 \%$, di lumbar dan lumbosakral sebanyak $13 \%$, torakolumbalis $12 \%$, dan sacrum $7 \%$.Penyebabnya belum ditentukan secara definitif, kemungkinan besar karena kongenital dan beberapa penelitian mengatakan bahwa kista ini dapat disebabkan oleh trauma, infeksi, atau peradangan.Kista arachnoid dikategorikan menjadi tiga tipe, tipe I (IA dan IB), tipe II dan tipe III. Terapi yang disarankan pada pasien asimptomatik adalah observasi sebagai terapi konservatif. Sedangkan terapi pembedahan eksisi kista secara utuh direkomendasikan untuk pasien dengan kerusakan neurologis yang berat, serta dilanjutkan dengan obliterasi pedikel komunikan dan repair watertight defek dural untuk menghambat mekanisme ballvalve. Dilaporkan satu kasus Seorang pasien perempuan berumur 46 tahun dengan keluhan utama nyeri punggung sejak 6 bulan sebelum masuk rumah sakit, dan dari hasil pemeriksaan penunjang berupa MRI didapatkan adanya Kista Subarachnoid Thorakal 12, dan pada pasien ini dilakukan tindakan operasi berupa unilateral laminectomy dan foraminectomy.
\end{abstract}

Kata kunci: Kista Arachnoid, thorakolumbal, unilateral laminectomy, foraminectomy

\begin{abstract}
Cyst of Arachnoid ekstradural represent scarce cyst and seldom as cause of backbone marrow compression and this is most often happened at middle shares and lower backbone. Approximately $65 \%$ of arachnoid cyst is located in middle and lower spine, $13 \%$ is located in lumbar and lumbosacral, $12 \%$ is located in thoracolumbal and $7 \%$ is located in sacrum. The causes have not determined definitely, most likely due to congenital. Some studies suuggest they the cyst can be caused by trauma, infection, or inflammation. Recommended therapy for asymptomatic patients is observation as conservative therapy. However, exicion of intact cyst as surgical therapy is recommended for severe neurogical damage. The excision is continued with the obliteration of pedicle communicant and repairing watertight dural defect to inhibit the ball valve mechanism. Reported one case A woman patient old age 46 year with especial sigh of back pain in bone since 6 months before entering hospital, and from result of MRI got the existence of Cyst of Subarachnoid at Thorakal 12, and this patient performed operation of unilateral laminectomy and foraminectomy.
\end{abstract}

Keywords: cyst of arachnoid, thoracolumbal, unilateral laminectomy, foraminectomy

Affiliasi penulis : 1. Pendidikan Dokter Spesialis Bedah FK Unand (Fakultas Kedokteran Universitas Andalas), 2. Bagian Bedah Divisi Orthopedii RSUP Dr. M. Djamil, Padang.

Korespondensi :shintaqorina@gmail.com Telp: 082172214337

\section{PENDAHULUAN}

Kista arachnoid ekstradural di tulang belakang merupakan kista yang langka dan jarang sebagai penyebab kompresi sumsum tulang belakang. Kista ini diduga timbul dari cacat bawaan pada dura mater, dan hampir selalu berhubungan dengan ruang subarachnoid intratekal melalui defek kecil di dura. ${ }^{1,4}$

Kista ini paling sering terjadi pada bagian tengah dan bawah tulang belakang (65\%), tetapi juga telah dilaporkan di lumbar dan lumbosakral (13\%), torakolumbalis $(12 \%)$, sacral $(7 \%)$.Penyebab kista ini belum ditentukan secara definitif, meskipun penyebab paling mungkin adalah kongenital. Beberapa dapat disebabkan oleh trauma, infeksi, atau peradangan. ${ }^{4}$

Lokasi kista dalam tulang belakang dan tingkat keparahan sumsum tulang belakang dan kompresi akar mempengaruhi presentasi klinis.Gejala dapat intermiten dan diperburuk oleh manuver Valsalva atau kekuatan posisi gravitasi. Remisi dan fluktuasi gejala telah dilaporkan pada sekitar $30 \%$ kasus. ${ }^{4,6}$
Dinding kista arachnoid ekstradural spinal biasanya terdiri dari jaringan ikat fibrosa dengan lapisan dalam sel arachnoid tunggal, namun, lapisan ini kadang-kadang tidak ada pada pemeriksaan histologi. Dalam beberapa kasus, kista ekstradural dapat menunjukkan ekstensi subtansi intradural.6,7

Beberapa peneliti berpostulat bahwa adanya mekanisme ball-valve di pedicle berhubungan dengan pergerakan CSF yang pulsatil, dan dapat menyebabkan ekspansi kista. 1,2,4

Magnetic resonance imaging (MRI) cukup efektif sebagai modalitas awal dalam mendiagnosis kista arachnoid dan tidak memerlukan injeksi media kontras intratekal. MRI juga dapat menentukan hubungan kista secara anatomi dengan struktur di sekitarnya..$^{2,3}$

Pada pasien yang asimptomatik, direkomendasikan hanya dilakukan observasi sebagai terapi konservatif. ${ }^{5}$

\section{KASUS}

Seorang pasien perempuan berumur 46 tahun masuk RS dengan keluhan utama nyeri punggung sejak 6 bulan sebelum masuk rumah 
sakit.Pasien juga mengeluhkan, nyeri terutama dirasakan setelah beraktivitas.Benjolan di punggung tidak ada, demam tidak ada, riwayat batuk-batuk lama tidak ada, riwayat penurunan berat badan tidak ada.BAK dan BAB tidak ada keluhan, pasien merupakan seorang pelatih senam.

Hasil pemeriksaan fisik didapatkan keadaan umum tampak sakit sedang, kesadaran kompos mentis kooperatif. Tekanan darah $120 / 70 \mathrm{mmHg}$, nadi $88 \mathrm{x} /$ menit, nafas $18 \mathrm{x} /$ menit, suhu $37,2^{\circ} \mathrm{C}$, mata konjungtiva tidak anemis, sklera tidak ikterik, thoraks dalam batas normal, abdomen dalam batas normal.

Status lokalis pada regio lumbal didapatkan pada tidak tampak adanya massa, dan tidak ada deformitas. Pada pemeriksaan ROM extremitas yang kanan didapatkan Hip flexi 5, Knee flexi 5, Ankle flexi 5, Toe extensi 5, sedangkan pada extremitas kiri pada pemeriksaan ROM didapatkan hasil Hip flexi 5, Knee flexi 5, Ankle flexi 5, Toe extensi 5.

Dari pemeriksaan laboratorium didapatkan hasil $\mathrm{Hb}$ 15,3 gr\% Leukosit 7.200 /mm3.

Pada pemeriksaan MRI lumbal didapatkan gambaran sebagai berikut:

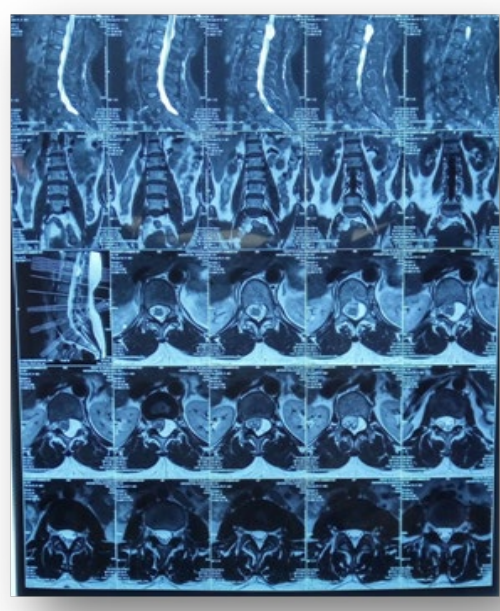

Gambar 1. MRI Lumbal
Pasien di diagnosa dengan Kista Subarachnoid Thorakal 12 dan direncanakan dilakukan unilateral laminectomy dan foraminectomy dalam anestesi umum.

Saat operasi, pasien di posisi prone dalam general anestesi dilakukan desinfeksi lapangan operasi dan dilakukan Insisi midline setinggi thorakallumbal, lalu Identifikasi kanal Thorakal 12 dan ekspos unilateral Thorakal 11 - Lumbal 2, dipasang pedikel screw pada Thorakal 11-Thorakal 12- Lumbal 1 dan lumabal 2. Lalu dilakukan unilateral laminectomy pada Thorakal 12 dan dilakukan Foraminectomy, tampak tonjolan massa kista di kiri dan dilakukan ekstirpasi kista. Rawat perdarahan dan dilakukan spinal fusion menggunakan 1 screw, setelah selesai, jahit lapangan operasi lapis demi lapis dan operasi selesai.

Pada intra operasi ditemukan kista seperti pada gambar berikut:
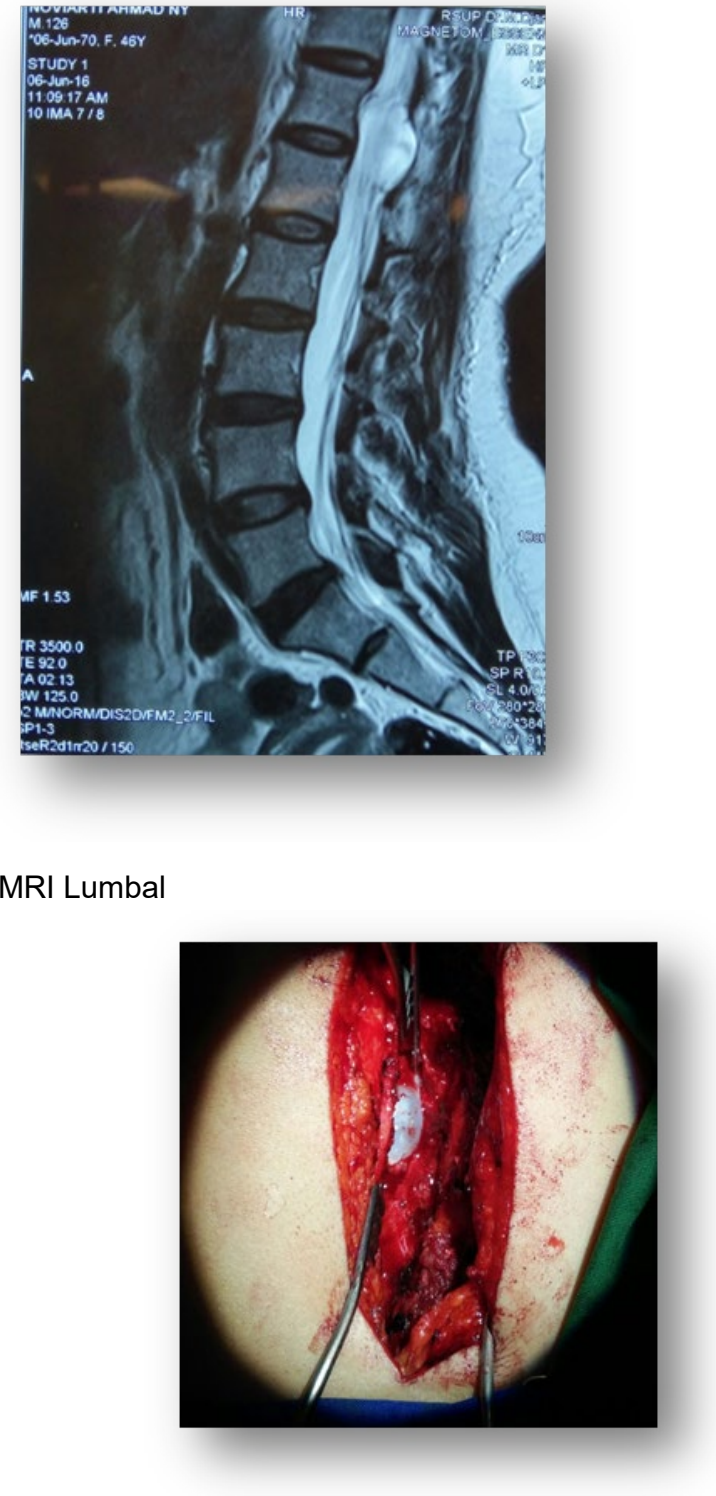

Gambar 2. Tampak kista pada Th12

Pasca operasi, pasien dirawat diruangan dengan keadaan sudah tidak terasa nyeri dan sudah tidak ada demam. Keadaan umum tampak sakit sedang, kesadaran compos mentis koperatif, tekanan darah $110 / 70 \mathrm{mmHg}$, nadi $80 \mathrm{x} /$ menit nafas $16 \mathrm{x} /$ menit, suhu $37,2 \mathrm{C}$. Mata konjungtiva tidak anemis, sklera tidak ikterik, thoraks dalam batas normal abdomen 
dalam batas normal.

Pada status lokalis regio lumbal tidak ditemukan massa maupun deformitas, ROM dalam batas normal pada kedua extremitas didapatkan hasil normal dengan masing-masing nilai Hip flexi 5, Knee flexi 5, Ankle flexi 5, Toe extensi 5, sedangkan pada extremitas kiri pada pemeriksaan ROM didapatkan hasil Hip flexi 5, Knee flexi 5, Ankle flexi 5, Toe extensi 5.

Pada saat kontrol pasca operasi dilakukan pemeriksaan rontgen ulang dengan hasil foto rontgen seperti berikut

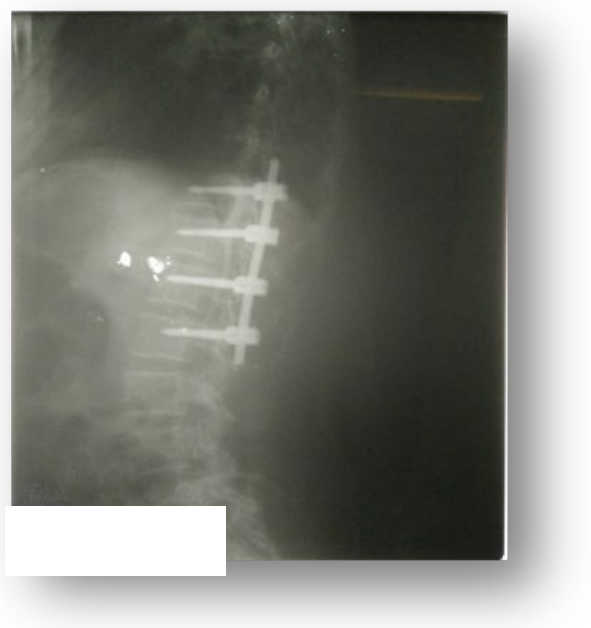

Gambar 3. Foto Rontgen post operasi

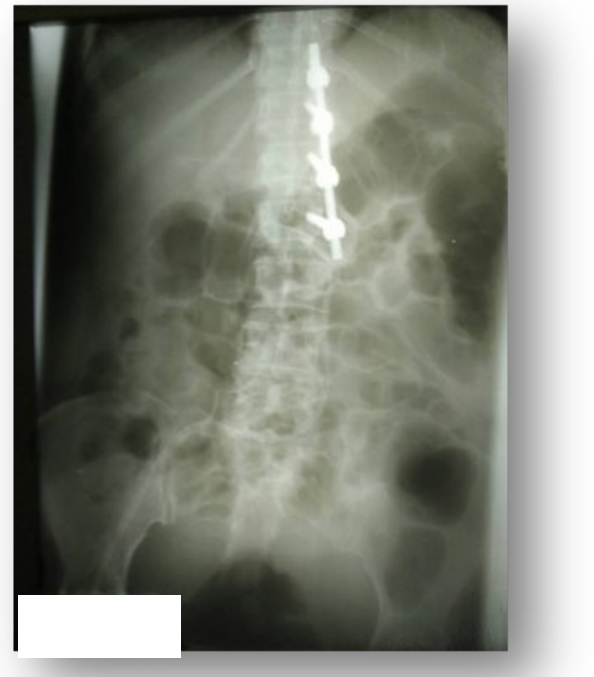

Gambar 4. Foto Rontgen Post operasi

\section{PEMBAHASAN}

Kista arachnoid ekstradural di tulang belakang merupakan kista yang langka dan jarang sebagai penyebab kompresi sumsum tulang belakang. Kista ini diduga timbul dari cacat bawaan pada dura mater, dan hampir selalu berhubungan dengan ruang subarachnoid intratekal melalui defek kecil di dura. Pengobatan pada pasien dengan gejala neurologis adalah operasi pengangkatan kista bersama-sama dengan ligasi pedikel yang berhubungan dan penutupan defek dural. 1,3,4,5

Kista arachnoid paling sering terjadi pada bagian tengah dan bawah tulang belakang (65\%), tetapi juga dilaporkan di lumbar dan lumbosakral sebanyak $(13 \%)$, torakolumbalis $(12 \%)$, sacral $(7 \%)$. Kista arachnoid ekstradural berkembang dari tonjolan arachnoid melalui defek kecil pada dura. Kista memiliki tonjolan yang berhubungan dengan ruang subarachnoid tulang belakang dan mengandung CSF (Gambar.5). 1,5,6,7

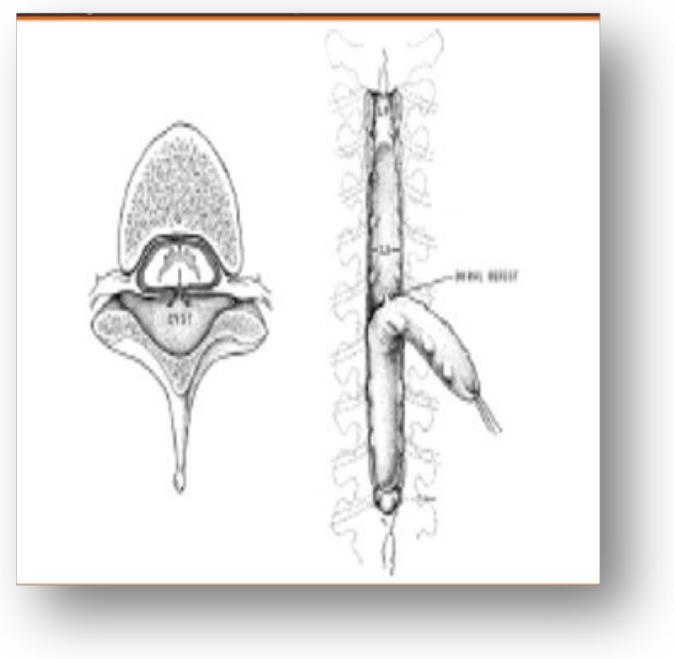

Gambar 5. Kista Arachnoid Ekstradural

Penyebab kista ini belum ditentukan secara definitif, meskipun penyebab paling mungkin adalah kongenital. Beberapa dapat disebabkan oleh trauma, infeksi, atau peradangan. ${ }^{3}$

a. Penampang tulang belakang menunjukkan defek dura dan hubungan kista dengan ruang subarachnoid. Tipe IA tulang belakang, kista arachnoid ekstradural dengan pedikel berhubungan di lokasi defek.

b. Magnetic resonance imagingberguna dalam mendeteksi massa, dan konsistensi CSF.Computed tomography myelography lebih baik untuk mendeteksi defek dural memungkinkan diagnosis yang akurat dari lesi ini. Kista yang bergejala terutama diobati dengan eksisi dan perbaikan defek pada dura. Pada artikel ini, kami meninjau gambaran klinis, fitur patologis, mekanisme patogenesis, karakteristik neuroimaging, dan manajemen operasi kista arachnoid ekstradural tulang belakang.

c. Kista arachnoid tulang belakang umumnya berkembang pada remaja, dan dua kali lebih banyak kasus terjadi pada laki-laki daripada pasien wanita.kista Thoracic biasanya terjadi pada remaja muda, sedangkan kista torakolumbalis dan lumbar biasanya muncul pada orang dewasa pada dekade keempat kehidupan. ${ }^{4,5}$

Lesi ini sering timbul ke arah dorsal dan sebagian bisa menonjol ke dalam foramen saraf yang berdekatan. Sebuah kista tunggal 
dapat extensike beberapa segmen tulang belakang, atau beberapa kista dengan dural defek yang terpisah dan pedikel yang berhubungan dapat membuat satu lesi. ${ }^{5}$

Pasien dengan kista torakal cenderung hadir denganparaparesis spastik progresif, tapi nyeri punggung umumnya jarang; sebaliknya, pasien dengan lumbar dan lumbosakral kista klasik hadir dengan nyeri punggung, radiculopathy, dan disfungsi berkemih dan defekasi. Secara keseluruhan, kelemahan motor biasanya lebih dominan daripada kehilangan sensorik. Gejala dapat intermiten dan diperburuk oleh manuver Valsalva atau kekuatan posisi gravitasi. ${ }^{1,2,4,5}$

Kista arachnoid Spinal telah diklasifikasikan ke dalam tiga kategori utama:

1. Tipe I : Kista ekstradural tanpa serabut saraf tulang belakang dibagi menjadi kista arachnoid ekstradural (Type IA) dan sacral meningoceles (Tipe IB)

2. Tipe II : Kista ekstradural dengan akar serabut saraf tulang belakang

3. Tipe III : Kista intradural

Dalam beberapa kasus, kista ekstradural dapat menunjukkan ekstensi subtansi intradural.Di hampir semua kasus kista Type IA, komunikasi CSF antara kista dan ruang intratekal subarachnoid melalui defek dural telah dilaporkan. 4,6,7,8,

Patogenesis dan asal pasti dari kista arachnoid ekstradural tipe IA pada spinal masih belum diketahui. Diduga kista ini bersifat kongenital, yang dapat melibatkan divertikula dura kongenital ataupun herniasi arachnoid yang melewati defek dural kongenital. 5

Bagian lengan dural dari akar serabut saraf atau junction dari lengan dan thecal sac adalah tempat yang paling umum terjadinya defek ini, tetapi defek ini jarang mengenai bagian midline dorsal dari thecal sac.Teori mengenai asal kista ini bersifat kongenital juga didukung oleh adanya laporan mengenai sindrom familial yang berupa adanya kista arachnoid multipel di spinal, lymphedema diekstremitas bawah (penyakit Milroy), dan distichiasis (bulu mata dua baris). ${ }^{1,2,5,8}$

Sebagai contoh, hilangnya elastisitas jaringan dan penurunan daya regang jaringan yang terjadi pada penderita sindrom Marfan mungkin berhubungan dengan adanyaectasia dural dalam proses perkembangan kista ini. ${ }^{2}$

Terdapat juga laporan mengenai kasus kista arachnoid spinal yang tidak berasal dari kelainan kongenital.Hubungan antara kista arachnoid spinal dengan arachnoiditis, pembedahan, dan trauma telah menyebabkan beberapa penelitiberpendapat bahwa kista ini mungkin timbul akibatdefek dural yang didapat. 2,7

Spiegel mannetal melaporkan kasus di mana hemosiderin yang mengandung makrofag pada dinding kista dapat menyebabkan paraparesis spastik 10 tahun setelah terjadinya cedera craniospinal.
Beberapa peneliti berpostulat bahwa adanya mekanisme ball-valve di pedicle berhubungan dengan pergerakan CSF yang pulsatil, dan dapat menyebabkan ekspansi kista. ${ }^{1}$

Menurut teori ini lonjakan tekanan yang intermiten dalam ruang subarachnoid akan berpengaruh terhadap kista, dan dapat menyebabkan mengalirnya cairan ke dalam kantong (Gambar 5). Ketika tekanan menurun lagi, adanya kompresi pada pedikel kista akan menghambat outflow cairan.Menurut hukum Laplace, badan kista akan memberikan tekanan yang cukup pada leher kista untuk menutup jalur aliran, karena radius dan ketegangan dinding yang lebih besar. ${ }^{1}$

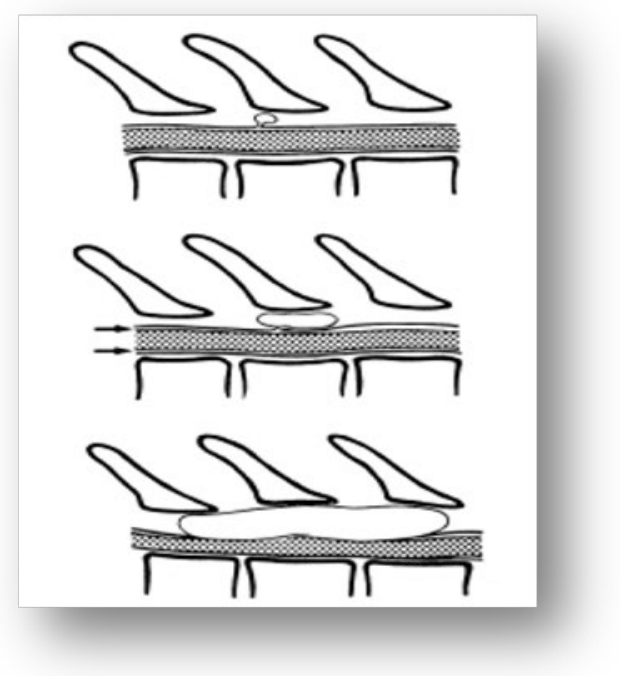

Gambar 6. Tekanan dalam ruang subarachnoid menekan kista. ${ }^{1}$

Faktor-faktor ini memungkinkan terjadinya pembesaran lebih lanjut pada kista dengan pulsasi CSF yang persisten.Mekanisme ball-valve ini telah diamati secara intraoperatif oleh Rohrer et al.Erosi tulang pada kanal spinal dapat menimbulkan mekanisme katup yang merupakan faktor utama penyebab tekanan CSF lebih besar dibanding tekanan hidrostatik normal didalam kista. ${ }^{6,8}$

Gambar atas menunjukkan lonjakan tekanan intermiten dalam ruang subarachnoid berpengaruh terhadap kista, dan menyebabkan terjadinya aliran ke dalam kantong.Ekspansi terjadi akibat perbedaan tekanan antara CSF intratekal dan ruang epidural.

Faktor-faktor ini memungkinkan terjadinya pembesaran lebih lanjut pada kista dengan pulsasi CSF yang persisten. Panah menunjukkan lonjakan cairan. Gambar bawah menunjukkan bahwa pada tahap akhir, thecal sac akan terkompresi, dan lebih banyak cairan yang didorong ke jalur valvelike, sehingga menyebabkan kista yang lebih besar dan menimbulkan kompresi pada sumsum tulang belakang. ${ }^{1}$

Magnetic resonance imaging (MRI) cukup efektif sebagai modalitas awal dalam mendiagnosis kista arachnoid dan tidak memerlukan injeksi media kontras intratekal. MRI juga dapat menentukan 
hubungan kista secara anatomi dengan struktur di sekitarnya. Karakteristik pencitraan kista arachnoid mirip dengan pemeriksaan intensitas CSF (Gambar 7). ${ }^{4}$

Lemak epidural yang membungkus lesi pada kutub superior dan inferior dapat dilihat pada potongan sagital T1-weighted MRI, yang juga dapat menunjukkan lokasi ekstradural lebih lanjut. Adanya vertebral body scalloping dan perluasan ke foramen neural bilateral yang berasal dari remodelling tulang menunjukkan adanya efek jangka panjang dari lesi.9,10

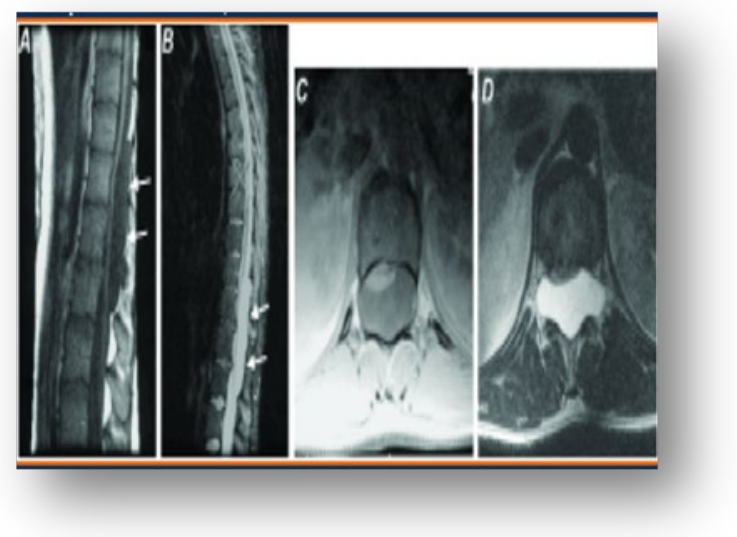

Gambar 7. Gambaran MRI potongan sagital T1weighted (A) T2-weighted (B) aksial T1-weighted (C) dan T2-weighted (D)

Perhatikan juga adanya kompresi dorsal yang berat dan pendataran pada thecal sac.Lemak epidural dapat dilihat di kutub superior dan inferior dari kista (A).Adanya scalloping dan remodelling pada batas tulang bagian dalam dari kanal tulang belakang disertai ekspansi bilateral foramen saraf menunjukkan adanya efek kista jangka panjang. Tidak ada jalur penghubung yang jelas antara kista dan ruang subarachnoid intratekal, meskipun terdapat satu jalur yang dicurigai.Magnetic Resonance Imaging (MRI) berguna dalam mendiagnosis kista, sedangkan CT myelography berguna dalam mendeteksi jalur penghubung antara kista tersebut dengan ruang subarachnoid. 9,10

Tekanan hidrostatik yang berlangsung lama dalam kista dapat menyebabkan perubahan pada tulang belakang, seperti melebarnya jarak interpedicular, erosi pedikel dan elemen posterior, scalloping vertebre bagian posterior, dan kyphoscoliosis. ${ }^{8,9}$

Konus medularis dan cauda equina terkompresi di bagian anterior.Juga terlihat remodelling tulang yang ekstensif dan scalloping pada bagian posterior.Kista ini juga meluas melalui foramen neural bilateral. ${ }^{9}$

Pada pasien yang asimptomatik, direkomendasikan hanya dilakukan observasi sebagai terapi konservatif. Terapi pilihan pada pasien dengan kerusakan neurologis yang simptomatik akibat kista arachnoid ekstradural di tulang belakang adalah eksisi kista secara utuh, dilanjutkan dengan obliterasi pedikel komunikan dan repair watertight defek dural untuk menghambat mekanisme ball-valve (Gambar 8).4,5,7

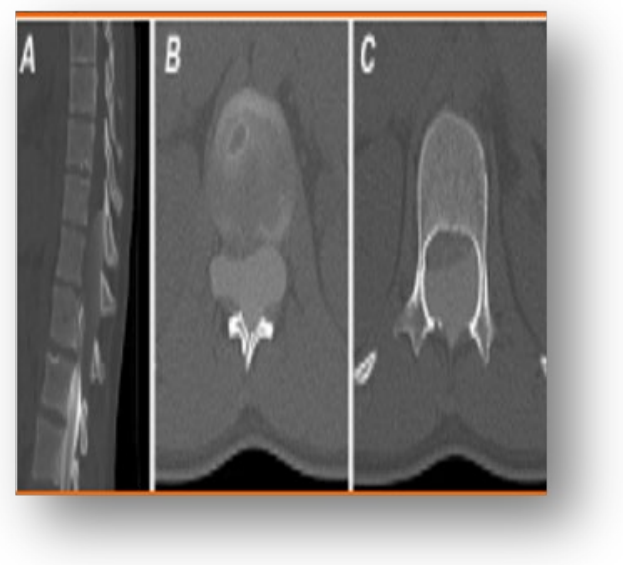

Gambar 8. Potongan sagital (A) dan aksial (B dan C) pada pemeriksaan CTmyelogram

Teknik ini memungkinkan dinding kista tetap utuh. Diseksi secara hati-hati dilakukan untuk mendekompresi thecal sac, kemudian defek dural dan pedikel komunikan di ruang subarachnoid diidentifikasi.

Total eksisi pada kista direkomendasikan untuk dilakukan bila memungkinkan untuk mencegah reakumulasi kista. Kista ini biasanya dapat di diseksi dan dielevasikan dari dura dengan mudah, Namun, pada kasus-kasus dimana terjadi adhesi fibrous padat, pemisahan kista dan dura menjadi berbahaya, Marsupiliasiluas pada kista dapat dilakukan dengan reseksi dinding dorsal kista dan menutup defek dural. 4,5

\section{DAFTAR PUSTAKA}

1. Choijy K, Leews S. Spinal extradural arachnoid cyst. Acta Neurochir 2006; 148:579-685.

2. Chaekh K, Shinh S. Septated extradural arachnoid cystin thoracolumbarspine causing myelopathy. JKorean NeurosurgSoc 2006; 40:381-421.

3. Liujk C, Kanp S. Spinal extradural arachnoid cysts: clinical radiological and surgical features. NeurosurgFocus 2007; 15:1-5.

4. Miyamotom K, Matsumotor I. Utility of preoperative magnetic resonance imaging myelography for identifying dural defects in patients with spinal extraduralar achnoid cysts: case report.Neurosurgery 2006; 59:10-12.

5. Kahramans, Aniki, Gocmens, Sirins. Extradural giant multilocu- lated arachnoid cyst causing spinal cord compression in achild. JSpinalCordMed 2008; 31:306-8.

6. Suryaningtyas. Multiple spinal extradural cysts occurring in a child. J Neurosurg 2007; 106 (2Suppl):158-61.

7. Nova D, Nemetht. Spinal extradural arachnoid cyst causing cordcompression in a15year-old girl : acasereport. Zen- tralbl Neurochir 2005; 66:43. 
8. Hidas N, Arimizu M. The transverse placement laminoplasty using titanium miniplates for there construction of the laminae in thoracic and lumbar lesion. Eur Spine 2006; 15:2-7.

9. Secer H, Anik I, Celik E. Spinal hydatid cyst mimicking arachnoid cyst on magnetic resonance imaging. J Spinal Cord Med. 2008; 31:6-8.

10.Beall D, Googe D, Emery R. Extramedullary intradural spinal tumors: a pictorial review. Curr Probl Diagn Radiol. 2007; 36:85-98. 